\title{
Os desafios encontrados na gestão escolar perante os alunos com necessidades
}

\section{especiais}

\author{
The challenges encountered in school management in the face of students with special needs \\ Los desafíos encontrados en la gestión escolar ante estudiantes con necesidades especiales
}

Recebido: 25/11/2021 | Revisado: 01/12/2021 | Aceito: 02/12/2021 | Publicado: 03/12/2021

\author{
Eduarda Ferreira Melo \\ ORCID: https://orcid.org/0000-0002-9864-6146 \\ Faculdade Guaraí, Brasil \\ E-mail: eduardamelo02@outlook.com \\ Izidorio Paz Fernandes Neto \\ ORCID: https://orcid.org/0000-0002-4868-1154 \\ Faculdade Guaraí, Brasil \\ E-mail: izidorio.neto@iescfag.edu.br
}

\begin{abstract}
Resumo
A presente pesquisa apresenta a gestão escolar e como ela promove o acolhimento na unidade de ensino, diante da presença dos alunos que necessitam de cuidados especiais. O gestor escolar ou diretor é o responsável por manter toda a escola em bom funcionamento bem como pelos planejamentos que norteiam as atividades acadêmicas, possibilitando a comunidade escolar a vivência dos novos desafios e aprendizagens. Vale lembrar que uma gestão democrática, deve proporcionar um trabalho claro envolvendo a participação ativa dos demais indivíduos, para isso, é necessário que a escola esteja aberta para novas mudanças como viabilizar a inclusão de alunos com necessidades especiais, fornecendo todo o suporte educacional de acordo com a lei. Esse estudo teve então como problemática compreender qual o papel do gestor diante da inclusão dos alunos com necessidades especiais no ambiente escolar. E para que esse processo de inclusão aconteça é de suma importância a família também estar inserida no ambiente para assim acompanhar o desenvolvimento da aprendizagem, em seguida vem o gestor promovendo adaptação quanto ao ambiente, materiais pedagógicos, sala de recursos, e a sala regular, aos professores e cuidadores, e em especial ao ambiente escolar que é onde se promove o ensino formando profissionais para o mercado de trabalho.
\end{abstract}

Palavras-chave: Gestão escolar; Inclusão; Acolhimento; Inovações.

\begin{abstract}
This research presents school management and how it promotes reception in the teaching unit, in view of the presence of students who need special care. The school manager or principal is responsible for keeping the entire school in good working order, as well as for the plans that guide academic activities, enabling the school community to experience new challenges and learning. It is worth remembering that a democratic management must provide a clear work involving the active participation of other individuals, for this, it is necessary that the school is open to new changes such as enabling the inclusion of students with special needs, providing all educational support accordingly. with the law. This study had the problem of understanding the role of the manager regarding the inclusion of students with special needs in the school environment. And for this inclusion process to happen, it is of paramount importance for the family to also be inserted in the environment to monitor the development of learning, then the manager comes to adapt to the environment, teaching materials, resource room, and regular room to teachers and caregivers, and especially to the school environment, which is where education is promoted, training professionals for the labor market.
\end{abstract}

Keywords: School management; Inclusion; Reception; Innovations.

\section{Resumen}

Esta investigación presenta la gestión escolar y cómo promueve la recepción en la unidad docente, ante la presencia de alumnos que necesitan cuidados especiales. El gerente o director de la escuela es responsable de mantener a toda la escuela en buen estado de funcionamiento, así como de los planes que guían las actividades académicas, permitiendo que la comunidad escolar experimente nuevos desafíos y aprendizajes. Cabe recordar que una gestión democrática debe proporcionar un trabajo claro que implique la participación activa de otras personas, para ello es necesario que la escuela esté abierta a nuevos cambios como posibilitar la inclusión de alumnos con necesidades especiales, brindando todo el apoyo educativo. de acuerdo con la ley. Este estudio tuvo el problema de comprender el rol del administrador en la inclusión de estudiantes con necesidades especiales en el entorno escolar. Y para que este proceso de inclusión suceda, es de suma importancia que la familia también se inserte en el entorno para monitorear el desarrollo del aprendizaje, luego el gerente viene adaptarse al entorno, materiales didácticos, sala de recursos y espacio regular para 
docentes y cuidadores, y en especial al ámbito escolar, que es donde se promueve la educación, formando profesionales para el mercado laboral.

Palabras clave: Gestión escolar; Inclusión; Recepción; Innovaciones.

\section{Introdução}

Ao se falar em gestão escolar, destaca-se a importância e o grande conceito que essa função possui. Um gestor escolar tem como dever administrar com responsabilidade a escola, pensando nas possíveis melhorias e atendendo com profissionalismo as necessidades a ele apresentas, proporcionando bem estar e a qualidade das atividades escolares.

Em referência ao termo gestão ou diretor, é comumente estabelecida uma associação direta para a palavra "poder", mas não é assim que funciona a administração de uma escola, trata-se da disposição com a qual o indivíduo irá conduzir e exercer seus deveres, o gestor escolar é submetido a várias responsabilidades, sendo a principal assegurar o funcionamento do ambiente escolar, assim como liderar a equipe de funcionários da escola para juntos atuar no desempenho e objetivos propostos, com isso fica evidente que a aprendizagem é o fator determinante do bom resultado da escola, sendo reflexo da dedicação dos alunos e profissionais da educação sob a qualidade de ensino (Pereira, 2018).

De acordo com Flores (2019) no Brasil na década de 1990, a gestão escolar passou a dominar e mudar com propósitos envolvendo tanto a teoria como o comportamento, tirando a visão de uma gestão administrativa que era interessada apenas nas questões burocráticas do cargo, buscando assim atualizar para uma gestão democrática que conta com a participação da comunidade em geral como, os alunos, funcionários, pais e professores, estimulando o crescimento da escola e o ensino dos alunos, diante das mudanças a impressão da administração empresarial ainda é sustentada nas unidades de ensino pois foi uma característica usada por muito tempo, no qual as U.E. faziam todo o trabalho de forma individual, assegurando independência e rendimento.

É necessário considerar a comunidade em conjunto com a família, garantir uma ligação com a escola, sendo capaz de ocasionar uma gestão democrática, compreendendo opiniões dadas, atuando com a participação e consciência de suas escolhas. A gestão democrática partilha da atuação de todos que estão habituados ao ambiente escolar, partindo dessa ideia a escola deve procurar uma colaboração que seja comunitária, trazendo participações nas tomadas de decisão da escola (Guimarães, 2018).

É imprescindível que o gestor conheça o ambiente de trabalho no qual ele está atuando, assim como no campo de ação que o mesmo estiver inserido e estar ciente das características de cada aluno, seja inserido com necessidades especiais ou não. No caso da educação especial é preciso identificar os aspectos que os alunos apresentam para que toda a equipe possa contribuir nessa inclusão, por isso é fundamental a formação continuada para que sirva como um apoio na qualidade da educação (Santana, 2015).

O papel dos gestores escolar diante da inclusão dos estudantes com necessidades especiais nas instituições de ensino, o efeito e a apresentação da comunidade em consideração a inclusão, são temas importantes, assim como a educação especial deve ser garantida e estabelecida nas redes de ensino (Freitas, 2014).

A LDB 9394/96 declara princípios que são democráticos que fazem referência de como é vista a educação inclusiva, e busca assegurar ensino de qualidade e equidade a todos. É uma nova impressão para que a escola atenda o maior número de demandas, trazendo assim resultados na educação, como a necessidade de fazer o atendimento aos alunos especiais sem preconceito trazendo um novo olhar para uma escola democrática. De acordo com o art. 54 do Estatuto da Criança e do Adolescente, (Lei n 8.069 de 13 de julho de 1990) é direito do aluno: "I - ensino fundamental, obrigatório e gratuito, inclusive para os que a ele não tiveram acesso na idade própria; II - progressiva extensão da obrigatoriedade e gratuidade ao ensino médio; III - atendimento educacional especializado aos portadores de deficiência, preferencialmente na rede regular de ensino [...]" (Brasil, 1990). 
O gestor que se abre para novas práticas, tendo envolvimento em reuniões pedagógicas, adequando a escola na política nacional de inclusão escolar e trazendo uma educação mais inclusiva, é o começo da construção para que uma escola se torne de fato inclusiva. É também uma forma de promover a valorização dos professores, o aperfeiçoamento da escola, quanto a sua estrutura fazendo um trabalho em equipe, o gestor é colocado como responsável pela maneira como os professores se comportam, assim eles se tornam capazes de alcançar e superar barreiras, construindo inovações nessa relação (Veiga, 2014).

Quando fica claro a característica entre gestão escolar diante da educação inclusiva e o meio didático que a mesma irá realizar, é necessário estimular com precisão as responsabilidades dos profissionais da educação, como os professores que acompanham o dia a dia de cada aluno, mas também é importante a presença dos pais, para que as escolas tenham organização e sejam inclusivas (Nascimento et al., 2018).

O presente trabalho tem como objetivo, identificar as responsabilidades do gestor escolar na inclusão dos alunos que necessitam de cuidados especiais nas salas de ensino regulares, fazendo assim uma análise de como ele atua na inclusão, e qual o seu compromisso diante da estruturação dos ambientes e dos recursos pedagógicos e como esses alunos são acolhidos no ambiente escolar. Esse estudo teve então como problemática compreender qual o papel do gestor diante da inclusão dos alunos com necessidades especiais no ambiente escolar.

\section{Metodologia}

\subsection{Caracterização da área de estudo}

O presente trabalho foi desenvolvido nas escolas públicas estaduais na cidade de Guaraí-TO (Figura 1) que possui uma área de 2278,41 km² (PNUD, 2019), localizada sob as coordenadas $08^{\circ} 50^{\prime} 03^{\prime \prime} \mathrm{S}$ e 48³0’37” W de longitude, e altitude de 259m, pertencente a mesorregião Ocidental do Tocantins e à microrregião de Miracema - TO, com aproximadamente $184 \mathrm{~km}$ da capital de Palmas. O município possui cerca de 26.403 habitantes (IBGE, 2021). A densidade demográfica corresponde a 10,23 hab./ km² (IBGE, 2010). A coleta de dados em questão foi levantada com a participação de gestores das seis unidades de ensino públicas estaduais situadas na cidade, sendo elas: Colégio Estadual Raimundo Alencar Leão, Esc. Est Antônio Alencar Leão, Esc. Est José Costa Soares, Esc. Est Irineu Albano Hendges, Colégio Militar Dona Anaídes Brito Miranda e Centro de Ensino Médio Oquerlina Torres. No entanto não houve retorno por parte de um destes gestores. 


\section{Figura 1. Mapa do Município de Guaraí}

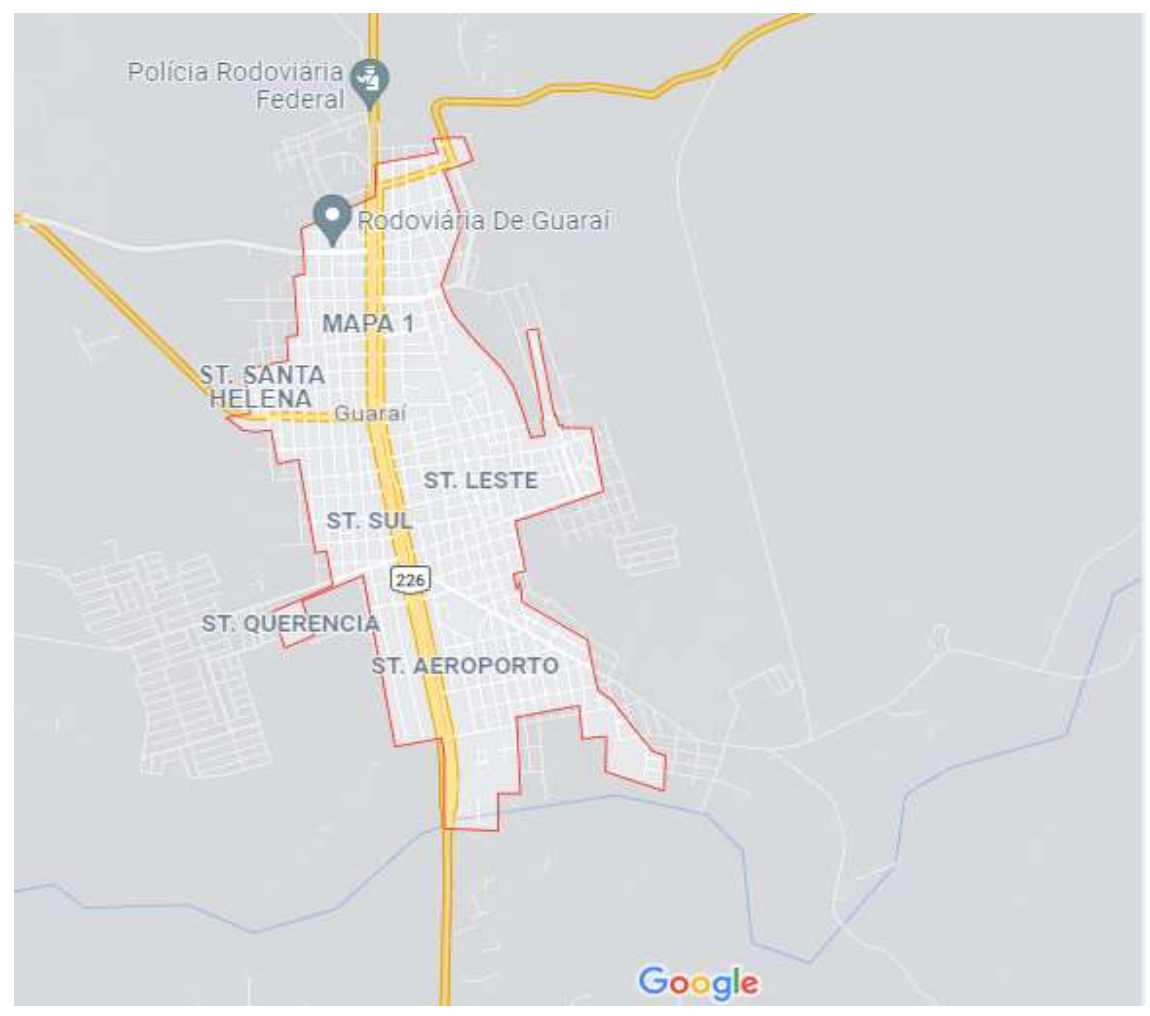

Fonte: Google Mapas (2021).

\subsection{Método de Coleta}

Para a realização do presente estudo foi utilizado o método qualitativo, através de um questionário online apresentado a todos os gestores das escolas estaduais da cidade, no período do dia 02 à 30 de setembro de 2021. Esse método de coleta foi escolhido por ser tratar de um público com muitas funções em seu cargo, sendo assim o questionário ficou disponível para ser respondido de acordo com o tempo livre de cada gestor.

Foram apresentadas no questionário três perguntas iniciais sendo duas objetivas e uma aberta, para levantar dados a respeito do conhecimento sobre os alunos e o ambiente em que o mesmo foi aplicado, e por fim cinco perguntas discursiva na qual os gestores tiveram total liberdade para responder, todas as perguntas foram voltadas aos alunos que necessitam de cuidados especiais dentro do ambiente escolar.

O questionário constitui uma série de perguntas elaboradas com a finalidade de gerar os dados pertinentes aos objetivos da pesquisa (Parasuraman, 1991). A utilização da internet como ferramenta auxiliar na troca e divulgação de informações, contribui para a melhoria e rapidez na realização da pesquisa. Ainda de acordo com Gil, Camelo e Laus (2013), o uso desse recurso também possibilita ao pesquisador o contato rápido e ágil com os participantes do estudo. Alguns estudos realizados comparando a coleta de dados por questionário impresso e questionário virtual não apontaram distinções relacionadas à obtenção de dados levantados (Fleming \& Bowden, 2009; Zuidgeest et al., 2011; Deshpande, Sampang \& Smith, 2010; Callas et al., 2010).

\section{Resultados e Discussão}

A pesquisa que teve como enfoque o acolhimento de alunos especiais no ambiente escolar por parte da gestão, no primeiro momento procurou identificar se na unidade de ensino possuía a presença de alunos com necessidades educacionais especiais, sendo assim foram concedidas duas alternativas. 
Na presente pesquisa foi confirmado que todas as escolas têm a presença de alunos que necessitam de cuidados especiais, cada um com sua particularidade na qual o ambiente escolar deve procurar atender esses alunos para que sejam inclusos nas salas de aula. É fundamental que a escola seja um local adequado para o acolhimento dos alunos, e que tenha uma equipe especializada em atendê-los, dando a eles todo o apoio necessário e o compromisso de uma inclusão (Corrêa, 2021).

A palavra inclusão se tornou de fato um grande desafio, que a maioria das escolas não quer enxergar e não quer ter em mãos a ação de garantir a todos os alunos direitos iguais seja qual for sua diversidade, a educação inclusiva tem de suma importância gerar discussões, mas vem gerando também o envolvimento da comunidade, apresentando atividades que mostra interesse na inclusão e na diminuição da desigualdade (Araujo, 2013).

No Brasil se iniciou falar em educação especial é inclusão na década e 1950, e todo esse desenvolvimento se deu pela criação de dois institutos, um para meninos cegos e outro para surdos e mudos, os dois no Rio de Janeiro, com esse atendimento especializado para os deficientes, foram abrindo espaço para uma nova construção de saberes, fazendo assim uma melhor aceitação dos indivíduos, depois com a proclamação da república a educação especial estendeu-se pelo Brasil, ainda de modo lento, assim as escolas começa a passar pelas mudanças necessárias para essa nova etapa na educação (Zanata, 2016).

É muito desafiador modificar uma escola para que ela seja inclusiva, mas é importante inserir esse novo método e também se torna um desafio, para que a escola seja encorajada a adotar um planejamento pedagógico para a construção de uma nova aprendizagem fazendo assim da escola um ambiente de direito de todos adquirir e transmitir conhecimento, a escola tem o dever de possibilitar uma educação com materiais e condições de qualidade, assim como o ambiente escolar, deve ser adaptado para esses alunos (Rocha, 2020).

Sabemos da importância que a sala de recurso tem para os alunos que necessitam de cuidados especiais, pois é nela que é transmitido o atendimento educacional especializado, juntamente com o ensino da sala regular proporcionando mais aprendizado para os educandos então foi abordado se nas unidades de ensino possuía sala de recurso.

Na referida pesquisa, foi afirmado pelos gestores que todas as unidades de ensino possuem uma sala de recurso, que é um ambiente ornamentado segundo as necessidades de cada aluno e de acordo com a estrutura da escola.

A sala de recurso tem como meta, dar aos alunos uma condição de atendimento com aprendizado diversificado e os métodos que ela oferece, e para que as atividades sejam desenvolvidas são levantadas muitas questões como o ambiente, a disposição dos profissionais, a compatibilidade entre a sala de recurso e a sala regular, observando a necessidade de cada aluno (Pasian et al., 2014).

É muito importante que o ambiente tenha ferramentas adequadas para aprimorar o espaço e materiais de acordo com as necessidades do estudante, assim como os gestores que tem o compromisso de afirmar um ensino de qualidade, garantindo profissionais qualificados para o domínio das salas (Prazeres et al., 2020).

E para finalizar a primeira parte do questionário, foi perguntado aos gestores quantos alunos tinha na unidade de ensino que necessitavam de cuidados especiais, as respostas podem ser observadas na tabela logo abaixo (Tabela 1). 
Tabela 1: Números referente a quantidade de alunos em cada escola

\begin{tabular}{c|c}
\hline Gestores & Quantidade de alunos \\
\hline G1 & 12 \\
\hline G2 & 14 \\
\hline G3 & Não sei exatamente \\
\hline G4 & 11 \\
\hline G5 & 16 \\
\hline
\end{tabular}

Fonte: Autores (2021).

A Tabela 1 indica a quantidade de alunos com necessidade especiais que cada escola entrevistada apresenta, apenas um gestor não soube responder quantos alunos tem na sua unidade de ensino. Essa pergunta se fez importante para que a partir dela os gestores possam promover qualidade no ensino e também procurar saber das importâncias de se conhecer as particularidades da escola, se o ambiente se encontra climatizado para receber o número de alunos que cada unidade possui, se o corpo docente possui professores capacitados para tal acolhimento e as demais demandas exigidas para que inclusão desses alunos venha acontecer.

O gestor escolar durante o seu cargo, precisa se empenhar para a administração da escola afim de gerar bons resultados, tudo isso se abrange nos recursos financeiros que é repassado para as unidades de ensino, manter o monitoramento das despesas gerados, a estrutura que a mesma se encontra, também como o horário de funcionamento das atividades escolares, a supervisão dos alunos e a busca por inovações, é de suma importância o gestor ter a colaboração do pedagogo da unidade para as funções e a elaboração dos projetos e objetivos da escola (Melo, 2019).

O gestor pode ser conhecido como grande mestre na educação, que colabora para que as mudanças na educação aconteçam, nos últimos tempos tem sido levantado a influência que a gestão escolar causa nos resultados de aprendizagem da educação, são conclusões das avaliações externas das organizações de conhecimento (Costa, 2019)

A segunda parte da entrevista foi composta por cinco perguntas discursiva, a primeira delas procurou saber qual a visão dos gestores diante da inclusão dos alunos com necessidades especiais no ensino regular (Tabela 2). 
Tabela 2: Visão dos gestores sobre a inclusão.

\begin{tabular}{|c|c|}
\hline Gestores & Respostas \\
\hline G1 & "A inclusão possibilita a interação e a igualdade dos estudantes" \\
\hline $\mathrm{G} 2$ & $\begin{array}{c}\text { "A inclusão é importante. Só que atualmente a escola está com números superior ao permitido de alunos } \\
\text { especiais. A lei permite apenas um por sala. e temos salas com número superior a três alunos com necessidades } \\
\text { especiais" }\end{array}$ \\
\hline G3 & "Eles necessitam dessa inclusão e que ao meu ponto de vista crescem aprendem e também ensinam" \\
\hline G4 & $\begin{array}{l}\text { "Trabalhar com a inclusão no dia a dia na escola é um desafio, pois nos deparamos com situações adversas. } \\
\text { Considero a Formação dos professores para trabalhar com os alunos, recursos financeiros e tecnológicos, } \\
\text { professores com capacitação específica são primordiais para uma inclusão de fato”" }\end{array}$ \\
\hline G5 & $\begin{array}{l}\text { "Como gestora de unidade escolar preciso assegurar uma aprendizagem de qualidade para todos os estudantes, } \\
\text { assim como o atendimento de todas as especificidades que os nossos estudantes necessitarem seguindo os } \\
\text { princípios do nosso modelo de gestão como o acolhimento e a pedagogia da presença" }\end{array}$ \\
\hline
\end{tabular}

Fonte: Autores (2021).

Foram obtidas diversas respostas, cada uma com suas particularidades enquanto gestor, como a preocupação da superlotação de alunos por sala referente à lei, nesse caso o número de alunos por turma é definido de acordo com a normativa das secretarias de educação. É uma situação que ocorre em várias escolas devido o aumento de alunos com necessidades e a falta de estrutura e profissionais capacitados para o ambiente escolar, apesar dos desafios, vale ressaltar a importância da inclusão e as possibilidades que ela desenvolve aos estudantes.

A inclusão deve ser feita tanto pelo gestor, como pelos coordenadores pedagógicos, diante dessa parceria, também se torna fundamental a participação dos professores, é visível os obstáculos durante o desenvolvimento, em muitos casos por não ter experiência nessa nova etapa da educação, não se sabe ao certo como alcançar um bom desempenho quando se trata de inclusão (Freitas, 2015).

O gestor é capaz de promover no ambiente escolar transformação inclusivas, pensando sempre na elaboração de metas e se as mesmas estão sendo cumpridas, dessa forma ele estabelece grandes transformações quando falamos em uma escola inclusiva, conquistando inovações na unidade de ensino (Pereira, 2011).

Sendo assim na segunda pergunta foi indagado aos gestores como era feito o acolhimento dos alunos no ambiente escolar, foi obtida as seguintes respostas conforme observa-se na Tabela 3. 
Tabela 3: Quanto ao acolhimento dos alunos.

\begin{tabular}{|c|c|}
\hline Gestores & Respostas \\
\hline G1 & “Os alunos são recebidos de forma igualitária com o tratamento especial que eles merecem” \\
\hline $\mathrm{G} 2$ & $\begin{array}{l}\text { "Não há bullying. É permitido a ele realizar as mesmas atividades que os demais, participam das atividades } \\
\text { militares. Fazem os mesmos movimentos de ordem unida que os demais. Somente a cobrança é que não é a } \\
\text { mesma que aqueles que não possuem necessidades especiais. Os instrutores já são orientados a fazer de conta de } \\
\text { que esses alunos acertaram todos os movimentos. Recebem as devidas condecorações como os demais" }\end{array}$ \\
\hline G3 & "Com ajuda da professora da sala de recurso são acolhidos como os outros alunos, de forma natural" \\
\hline G4 & "Parceria Família e Escola para conhecer a realidade dos alunos, fomentar um ambiente livre de preconceito" \\
\hline G5 & $\begin{array}{l}\text { "Diariamente são acolhidos ao adentrarem os portões da escola pela professora auxiliar (dependendo da sua } \\
\text { deficiência), orientadora educacional, professor inspetor, porteiro e diretora" }\end{array}$ \\
\hline
\end{tabular}

Fonte: Autores (2021).

Com os resultados do questionário podemos perceber que os alunos estão sendo recebidos na escola da maneira que devem ser acolhidos, principalmente ao chegar no ambiente e nas atividades diárias, com a supervisão do professor auxiliar.

A inclusão se tornou um dos grandes problemas na educação, que resulta em mudanças no ambiente escolar, o mais importante é considerar a história pessoal de cada criança, cuidar igualmente de todos, fazendo da inclusão apesar dos obstáculos, uma ação que busca a cada dia crescer para formar cidadãos de bem, pois a inclusão é uma ação que deve ser vista também fora da sala regular, é um movimento que envolve toda a escola (Saldanha, 2015).

Uma escola inclusiva não é apenas o acolhimento dos alunos com necessidades especiais, mas também de todos os integrantes que fazem parte do processo escolar e que de certo modo são afastados das atividades escolares, nesse caso a escola deve procurar atender os alunos, oferecendo um ambiente de ensino de qualidade, sendo assim buscando novas transformações na organização da escola diante das diferenças de ensino (Barbosa, 2011).

A educação especial é um grande trajeto que envolve toda uma escola e a comunidade na busca de qualidade para o ensino e avanço no atendimento das crianças com necessidades especiais (Closs, 2014). Então se torna muito importante que os gestores faça acontecer o acolhimento aos alunos, a partir da sua chegada até a sua saída e também que promova essa qualidade de igualdade aos demais, assim os alunos serão inclusos da melhor forma pela escola e colegas.

A terceira pergunta questionava ao gestor, se ele como mediador do processo de inclusão assegurava aos alunos adaptação ao ambiente e materiais adequados, caso a sua resposta fosse sim, também foi questionado de que forma (Tabela 4). 
Tabela 4: Adaptação quanto ao ambiente e materiais.

\begin{tabular}{|c|c|}
\hline Gestores & Respostas \\
\hline G1 & "Sim. A escola adquiriu materiais pedagógicos de acordo a necessidade dos alunos com alguma deficiência" \\
\hline $\mathrm{G} 2$ & $\begin{array}{c}\text { "São identificados aqueles que chegam sem o laudo. Procuramos a família para que levem o aluno ao profissional } \\
\text { de saúde para investigar as necessidades adequadas a ele. Após, a identificação da necessidade de cada um, é } \\
\text { encaminhado à sala de recurso para iniciar o aprendizado conforme cada necessidade. O aluno não é tratado com } \\
\text { diferenças. Sempre é tratado com igualdade dentro de sala de aula e acompanhado por um cuidador quando } \\
\text { necessário" }\end{array}$ \\
\hline G3 & "Sim, colocando os na frente e com trabalhos adaptados para a realidade de cada um" \\
\hline G4 & $\begin{array}{c}\text { "A escola já é adaptada para receber os alunos, alguns materiais necessários, os professores produzem e a escola } \\
\text { adquire também com recursos enviados pela Secretaria de Educação" }\end{array}$ \\
\hline G5 & $\begin{array}{c}\text { "Sim. Mesmo que não seja em condições perfeitas, mas as adaptações quanto a acessibilidade, alimentação e } \\
\text { materiais são realizados e disponibilizados para todos os estudantes" }\end{array}$ \\
\hline
\end{tabular}

Fonte: Autores (2021).

Em decorrência da Covid-19, o questionário foi aplicado de modo online, desse modo não foi possível realizar uma visita aos locais de acesso dos alunos, como a sala de ensino regular e a sala de recurso, com base nas respostas foi descrito a forma que cada gestor faz para a que aconteça a adaptação dos alunos no ambiente escolar, segundo as falas, todas as escolas são adequadas para receber as necessidades dos alunos.

A escola busca ofertar uma aprendizagem com todo conforto aos alunos, mas a mesma espera que os gestores e a comunidade que envolve pais e professores estejam aflitos com a forma de ensino e que sejam capazes de aprimorar a formação desses alunos, além disso, é necessário o conhecimento de como estar sendo aplicado o ensino aos alunos, assim como os alunos devem ter consciência do que estar sendo trabalhado, pois é através dele que vão ser formados seus conhecimentos (Gelatti, 2013).

A adaptação no ambiente escolar é formada no intuito de criar novos métodos que sejam capazes de estar diante dos obstáculos enfrentados pelos alunos, é esperado que seja preparada essa adaptação para que possa atender as particularidades dos alunos que necessitam do atendimento especializado no ambiente escolar, não e necessário mudanças nos documentos da escola, apenas alguns ajustes para garantir os alunos participação nas atividades (Costa, 2011).

As escolas brasileiras precisam ser mais capacitadas para acolher os alunos que necessitam de cuidados especiais, em muitas escolas ainda não tem as adaptações fundamentais para que os alunos sejam inclusos, a educação é um dos meios mais importantes para não acontecer a exclusão social, portanto é necessário esse investimento em condições que beneficie os alunos (Castro, 2018).

A quarta pergunta teve como propósito averiguar se o gestor escolar tem autoridade para buscar recursos e projetos que ajudem o aluno com necessidade especial, e que também acrescente na formação de professores e no ambiente escolar (Tabela 5). 
Tabela 5: Recursos e projetos.

\begin{tabular}{|c|c|}
\hline Gestores & Respostas \\
\hline G1 & "Sim" \\
\hline G2 & $\begin{array}{c}\text { "Os profissionais da sala de recursos da nossa escola possuem cursos na área. Os que chegam sem o curso são } \\
\text { levados a capacitação para tal. Também possuímos parcerias com a Diretoria Regional de Ensino, onde sempre } \\
\text { nos encaminham profissional com especialização em libras, devido termos um aluno com necessidades em } \\
\text { linguagem de Libras” }\end{array}$ \\
\hline G3 & "Não sei responder" \\
\hline G4 & "Sim, junto a SEDUC-TO" \\
\hline G5 & $\begin{array}{l}\text { "Sim. Sendo uma instituição estadual temos a Assessoria da Educação Especial na DREJE de Guaraí e na } \\
\text { Secretaria da Educação, Juventude e Esporte em Palmas a Gerência da Educação Especial onde somos atendidos } \\
\text { em nossas demandas assim como os profissionais que trabalham neste atendimento especializado recebem } \\
\text { formações, participam de encontros, alinhamentos e ainda temos a comunidade local como parceiros neste } \\
\text { trabalho de inclusão e amor" }\end{array}$ \\
\hline
\end{tabular}

Fonte: Autores (2021).

Sobre o questionamento de recursos e projetos, pelas respostas podemos perceber que as escolas têm profissionais capacitados para o atendimento dos alunos e contam com o apoio dos devidos órgãos que firmam parcerias com as escolas para que seja realizado melhorias e inovações no ensino. Somente um gestor não soube responder.

A educação especial é marcada por diversos obstáculos, envolvendo os professores e as equipes escolares, ainda, mais quando se é discutido a respeito das crianças especiais, é necessário que os ambientes tenham profissionais capacitados para que seja realizado um melhor conceito das salas de aula e que os profissionais continuem a atuar em busca de aprendizagens para assim receberem e ensinarem com excelência os alunos (Althaus, 2011).

Sabemos que a educação ainda se encontra distante do alcance de todas as pessoas, por isso devemos buscar construir aprendizagens que sejam essenciais a todos os alunos, e que eles possam criar vínculos com o ambiente de ensino, o maior estímulo é tornar as unidades de ensino capazes de ofertar ensino a todos, principalmente aos que precisam de atendimento especializado dentro da escola e nas salas de aulas (Cruz, 2018).

A gestão escolar tem a função de auxiliar ou não na inclusão, ajudando nas atividades que os professores ministram na sala de aula, como também oferecer um ambiente agradável, e ser um gestor que ouve a sua comunidade escolar, principalmente os alunos, para que assim eles possam se sentir confortáveis no ambiente escolar e assim dar o suporte as necessidades de cada um que estar inserido na escola (Silva, 2011).

Para finalizar o questionário, na quinta pergunta foi interrogado como é realizado o controle dos alunos que necessitam de cuidados especiais na sala regular de ensino, se eles são inclusos de modo geral, como os outros alunos ou se frequentam apenas a sala de recurso (Tabela 6). 
Tabela 6: Controle dos alunos na sala regular e sala de recurso.

\begin{tabular}{|c|c|}
\hline Gestores & Respostas \\
\hline G1 & "São incluídos de forma geral" \\
\hline $\mathrm{G} 2$ & $\begin{array}{l}\text { "A entrada desse aluno é pelo sistema da seduc. Isso tem causado problemas no acesso de um número superior ao } \\
\text { permitido por sala. Assim, não há controle ao acesso. Após já está na escola esse aluno identificado com } \\
\text { características de necessidades especiais, é acionado a família para providenciar o profissional que consiga } \\
\text { identificar se realmente trata-se de um aluno especial ou não" }\end{array}$ \\
\hline G3 & "São inclusos, mas frequentam também a sala de recurso no horário oposto" \\
\hline G4 & $\begin{array}{l}\text { "Contamos na escola com professores auxiliares para acompanhar os alunos em sala de aula e auxilia - lós em suas } \\
\text { dificuldades, os professores desenvolvem atividades adaptadas conforme a necessidade de cada aluno" }\end{array}$ \\
\hline G5 & $\begin{array}{l}\text { "A frequência dos nossos estudantes é realizada diariamente pela orientadora educacional, professoras auxiliares e } \\
\text { professores inspetores. Eles participam das aulas regulares pela manhã com todos os outros estudantes sendo } \\
\text { acompanhados pelos professores regentes e auxiliares e no período vespertino recebem atendimento } \\
\text { individualizado pelas professoras auxiliares na execução de suas atividades como também com a professora da sala } \\
\text { de recurso seguindo um cronograma de atendimento" }\end{array}$ \\
\hline
\end{tabular}

Fonte: Autores (2021).

Concluímos que com a última pergunta do questionário, foi afirmado que os alunos matriculados com necessidades especiais, têm recebido o devido atendimento e são inclusos na sala regular de ensino, igual aos demais alunos e frequentam também a sala de recurso.

É preciso compreender o conceito dos três cargos importantes dentro da escola para a inclusão, a gestão escolar, o professor da sala de recurso e o da sala de ensino regular, na qual o aluno tem participação, pois o ambiente escolar deve acolher a todos sem preconceito, seja um aluno com necessidades especiais ou não, desse modo poderá ocorrer transformações na educação (Flores, 2018).

A fim de assegurar aos alunos atuação nas atividades educacionais, espera-se que o professor da sala de recurso busque assessorar aos demais da escola para acontecer uma educação adaptável aos alunos com necessidades especiais, através das metodologias aplicadas, fazendo assim possíveis acomodações curriculares, promovendo a diversidade fundamental ao ensino (Oliveira et al., 2018)

Muitas vezes pensamos que a inclusão é a simples ação do aluno estar incluído no sistema da escola, mais se dar também pelo compromisso dos profissionais e a estrutura do ambiente, considerando que ao ensinar os alunos igualmente, estarão gerando resultados no aprendizado de todos e também em sua carreira de convívio com o mundo fora da escola, diminuindo a desigualdade e trazendo equilíbrio para uma vida em comunidade (Moreira, 2014).

\section{Conclusão}

Através do questionário realizada com os gestores das escolas estaduais do município de Guaraí, compreende-se que é de suma importância o acolhimento de alunos que necessitam de cuidados especiais durante o seu desenvolvimento educacional. Para a unidade de ensino que realiza o acolhimento, são novos desafios a serem considerados, principalmente quando é cobrado objetivos, melhorias profissionais e estruturais dentro desse processo de inclusão. A intenção é que os gestores procurem cada vez mais melhorar seus aspectos educacionais, visando sempre trazer tranquilidade para aqueles que estão diariamente com o aluno, que são os professores e cuidadores. 
É preciso que sempre tenha comunicação dos gestores com a equipe escolar, para assim promover um ensino de acordo com a necessidade de cada aluno, por esse lado também se torna indispensável a participação da família nas atividades e especialmente no acolhimento. É necessário que os gestores sejam sempre ativos na busca por recursos, que venha acrescentar no ambiente, proporcionando bem estar aos alunos e professores, juntamente com a capacitação dos mesmos. Em vista disso, é importante que mais pesquisas e trabalhos sejam feitos acerca do tema, dado sua importância para assegurar um ensino inclusivo de qualidade.

Contudo, espera-se que a análise realizada, some para o conhecimento da sociedade e de modo especial na carreira profissional dos gestores, para que assim eles possam exercer sua função em condições de oferecer aos alunos um acolhimento de acordo com a sua necessidade em particular, promovendo também a inclusão nas escolas.

\section{Referências}

Althaus, L. G. (2011). Gestor educacional: mediador da inclusão. (Monografia). Universidade Federal de Santa Maria, Santa Maria, RS, Brasil.

Araujo, C. R. S. (2013). Os desafios da inclusão do Portador de Necessidades Especiais Auditivas em escolas do ensino regular no Brasil: uma revisão da literatura. (Monografia). Universidade Federal do Recôncavo da Bahia, Cachoeira, BH, Brasil.

Barbosa, L. V. (2011). Construindo uma escola inclusiva: o impacto do espaço escolar na promoção do acolhimento. (Trabalho de Conclusão de Curso). Faculdade de Educação da Universidade de Brasília, Brasília, DF, Brasil.

Brasil. Governo Federal. Estatuto da Criança $e$ do Adolescente. Lei federal, v. 8, $1990 . \quad$ Recueprado de https://www.cidadaniaesaber.org.br/projetos.

Callas, P. W., Solomon, L. J., Hughes, J. R., \& Livingston, A. E. (2010). The influence of response mode on study results: offering cigarette smokers a choice of postal or online completion of a survey. Journal of Medical Internet Research, 12(4), e1414.

Closs, K. M. (2014). Um diálogo sobre a inclusão a partir da gestão escolar e seus atores. (Monografia). Universidade Federal de Santa Maria, Agudo, RS, Brasil.

Costa, S. M. D. L. (2011). Adaptação curricular na escola inclusiva e seus reflexos no processo da aprendizagem e socialização dos alunos com necessidades educacionais especiais. (Monografia). Universidade de Brasília, Instituto de Psicologia, Brasília, DF, Brasil.

Costa, Z. R., \& Almeida, V. O. (2019, outubro). Gestão escolar e o atendimento de alunos com Necessidades Educacionais Especiais (NEE): da realidade à possibilidade de inclusão em uma escola pública. Anais do Congresso Brasileiro Ciência e Sociedade: Inovação, Diversidade e Sustentabilidade, Teresina, PI, Brasil.

https://scholar.archive.org/work/5c6kekhffvgslfwtj5txcyhof4/access/wayback/https://proceedings.science/proceedings/100107/_papers/1105 98/download/fulltext_file1

Cruz, C. F. (2018). As implicações do gestor escolar no processo de inclusão de alunos com Necessidades Educacionais Especiais (Dissertação de Mestrado). Universidade Fernando Pessoa, Porto, Brasil.

Corrêa, D. da S. (2021). A importância da inclusão de pessoas com necessidades especiais na rede regular de ensino. (Trabalho de Conclusão de Curso). Escola Superior Aberta do Brasil, Vila Velha, ES, Brasil.

Castro, G. G. de, Abrahão, C. A. F., Xavier, Â., do Nascimento, L. C. G., \& Figueiredo, G. L. A. (2018). Inclusão de alunos com deficiências em escolas da rede estadual: acessibilidade e adaptações estruturais. Revista Educação Especial, 31(60), 93-105.

Damasceno, L. M. D. S., Silva, P. G. D., Ramos, A. S. M., Cortez, A. E. G., \& Bastos, E. D. M. (2014, outubro). Potencialidade e limitações da coleta de dados através de pesquisa online. XVII Seminário em Administração (SEMEAD), 7. http://sistema.semead.com.br/17semead/resultado/trabalhosPDF/1099.pdf

Deshpande, A. V., Sampang, R., \& Smith, G. H. (2010). Study of botulinum toxin A in neurogenic bladder due to spina bifida in children. ANZ journal of surgery, 80(4), 250-253.

Fleming, C. M., \& Bowden, M. (2009). Web-based surveys as an alternative to traditional mail methods. Journal of environmental management, 90(1), 284-292. 
Flores, A. S. (2018). Gestão Escolar e Educação Inclusiva: articulação entre o atendimento educacional especializado e o ensino regular. (Dissertação de Mestrado). Instituto de Biociências, Letras e Ciências Exatas da Universidade Estadual Paulista "Júlio de Mesquista Filho", São José do Rio Preto, SP, Brasil.

Flores, L. M. M. (2019). A gestão escolar e a educação inclusiva: um estudo de caso de uma escola de educação infantil do município de São Sebastião do Caí. (Trabalho de Conclusão de Curso). Instituto Federal de Educação, Ciência e Tecnologia do Rio Grande do Sul, Feliz, RS, Brasil.

Freitas, P. R. D. (2014). O papel da gestão escolar na inclusão dos alunos com necessidades educativas especiais. (Monografia Especialização). Universidade de Brasília, Brasília, DF, Brasil.

Freitas, J. F. F. de, \& de Araújo, P. F. (2015). A inclusão de crianças com deficiência e o envolvimento dos gestores escolares. Educação e Fronteiras, 5(15), 75-84.

Gelatti, L. D. (2013). Contribuições da gestão escolar na qualidade da educação. (Monografia - Especialização). Universidade Federal de Santa Maria, Santa Maria, RS, Brasil.

Guimarães, M. C. (2018). Gestão escolar e os desafios da prática pedagógica na educação especial. (Monografia - Especialização). Universidade Federal de Santa Maria, Três Passos, RS, Brasil.

Melo, D., Martins, D., Bastos, D., DO, V., \& Souza, H. L. (2019). Gestão democrática: um olhar contemporâneo a partir do ambiente escolar. (Trabalho de Conclusão de Curso). Faculdades Doctum de Serra, Serra, Brasil.

Moreira, S. M. (2014). A inclusão das crianças e adolescentes com necessidades especiais na rede regular de ensino. (Trabalho de Conclusão de Curso - Especialização). Universidade Tecnológica Federal do Paraná, Medianeira, PR, Brasil.

Nascimento, B. A. B. do, de Araújo Penitente, L. A., \& Mosca Giroto, C. R. (2018). Gestão escolar e educação inclusiva: análise da produção científica na área de Educação Especial. Actualidades Investigativas en Educación, 18(3), 517-543.

Oliveira, I. C., \& Vasques-Menezes, I. (2018). Revisão de literatura: o conceito de gestão escolar. Cadernos de pesquisa, 48, 876-900.

Pasian, M. S., Mendes, E. G., \& Cia, F. (2014). Salas de recursos multifuncionais: revisão de artigos científicos. Revista Eletrônica de Educação, 8(3), 213-225.

Pereira, D. J. H. D. S. (2011). O papel do gestor na busca por uma escola inclusiva no município de Novo Gama-Goiás. (Monografia Especialização). Universidade de Brasília, Universidade Aberta do Brasil, Brasília, DF, Brasil.

Pereira, L. M. (2018). Os desafios da gestão escolar: exercício da liderança para a condução do trabalho em equipe.

Prazeres, R. S., \& de Magalhães, V. de O. (2020). Tecnologias Assistivas: o fazer estratégico de uma professora da sala de recursos multifuncional. Revista Docência e Cibercultura, 4(1), 41-54.

Rocha, V. M. da. (2020, outubro). Perspectiva histórica e desafios da escola pública: dificuldades da escola pública na inclusão de alunos com necessidades especiais. Anais do VII Congresso Nacional de Educação, Maceió, AL, Brasil. https://editorarealize.com.br/editora/anais/conedu/2020/5fdc952ecdf29_18122020084030.pdf

Rodrigues, C. M. L., Chagas, P. C., \& Corrêa, C. R. (2015). Pesquisa mediada pela internet: possibilidades de aplicação de entrevista online nas ciências da gestão. Negócios em Projeção, 6(2), 69-77.

Saldanha, S. N., Garcia, C. A. X., \& Zaupa, P. (2015). A Inclusão de crianças com necessidades educacionais especiais na prática pedagógica de uma escola municipal do município de Vila Nova do Sul. Revista Monografias Ambientais, 14, 143-154.

Santana, A. (2015). A gestão escolar no contexto da educação inclusiva: a educação especial em questão. Revista de Educação do Vale do Arinos-RELVA, 2(1).

Zanata, C. (2016). Inclusão escolar: conquistas e desafios. Cadernos de Educação: Ensino e Sociedade, Bebedouro-SP, 3 (1): 15-30, 2016

Zuidgeest, M., Hendriks, M., Koopman, L., Spreeuwenberg, P., \& Rademakers, J. (2011). A comparison of a postal survey and mixed-mode survey using a questionnaire on patients' experiences with breast care. Journal of medical Internet research, 13(3), e68. 